\title{
THE ROBUSTNESS OF THE ANCHORING EFFECT IN VALUATION TASKS
}

\author{
Magdalena Brzozowicz* \\ University of Warsaw
}

\begin{abstract}
I examined the robustness of the anchoring effect with respect to the method of valuation, type of anchor and the availability of information about the presented product. In four different laboratory experiments, I elicited consumerwillingness to pay (WTP) for cosmetic product manipulating anchoring conditions (low vs. high anchor or no anchor vs. high anchor). I observed that only the market anchor (the real price of a similar product) had an impact on WTP. I also found that the strength of the anchoring effect is lower in incentivised valuation tasks compared to hypothetical anchoring questions (I observed a significant anchoring effect only in experiment with declarative valuations). My findings suggest that the robustness of the anchoring effect is limited.
\end{abstract}

Key words: anchoring effect, laboratory experiment, WTP, valuation of products.

\section{SIEA EFEKTU ZAKOTWICZENIA W ZADANIACH ZWIAZZANYCH Z WYCENĄ PRODUKTÓW}

Streszczenie: Wniniejszym artykule zbadano stabilność efektu zakotwiczenia, uwzględniając uzyta metodę wyceny, typ kotwicy i dostępność informacji o prezentowanym produkcie. W czterech róznych eksperymentach laboratoryjnych pozyskano graniczne ceny kupna (WTP) produktu kosmetycznego, manipulujac przedstawionq uczestnikom kotwica (niska vs. wysoka kotwica lub brak kotwicy vs. wysoka kotwica). Zaobserwowano, ze jedynie kotwica rynkowa (realna cena podobnego produktu) miała wptyw na WTP za prezentowany produkt. Wskazano również, że siła efektu zakotwiczenia, $w$ porównaniu z wycena hipotetyczna, jest mniejsza $w$ przypadku zastosowania zachęt finansowych do wskazywania rzeczywistej wyceny. Zaobserwowano istotny statystycznie efekt zakotwiczenia

* Magdalena Brzozowicz, University of Warsaw, Długa 44/50, 00-241 Warsaw, Poland,

e-mail: mbrzozowicz@wne.uw.edu.pl 
jedynie w eksperymencie z wycena deklaratywna. Wnioski z badania sugeruja, że odporność efektu zakotwiczenia jest ograniczona.

Stowa kluczowe: efekt zakotwiczenia, eksperyment laboratoryjny, skłonność do zapłaty, wycena produktów.

\section{INTRODUCTION}

We speak of anchoring when the presentation of an arbitrary number (the anchor) affects an individual's numerical forecast, estimation, or evaluation. This heuristic was popularised by Tversky and Kahneman (1974). In their laboratory experiments, subjects were asked to provide their estimations of various values, such as the fraction of African countries belonging to the United Nations. At every turn of the experiment, they were asked to consider if the target value was lower or higher than the outcome generated by a wheel of fortune immediately before. Then, they were asked to give their estimation. Their answers were strongly correlated with the (obviously irrelevant) reference value. According to Tversky and Kahneman, participants anchored on the reference value from a wheel of fortune and showed insufficient adjustment, so that a high anchor contributed to overestimation and a low one to underestimation.

An alternative theoretical explanation, called the selective accessibility, was provided by Strack and Mussweiler (1997). According to the authors, respondents' estimations tends to be close to the anchor, because the anchor-consistent information is more easily accessible.

In the subsequent literature, other theoretical insights were proposed, e.g. a scale distortion theory of anchoring (anchor value changes the perception of the response scale; Frederick \& Mochon, 2012) or attitude change perspective (extreme or implausible anchors may be ignored, leading to less attitude change; Wegener et al., 2001). Therefore, the discussion of the mechanism underlying the anchoring effect remains open (Tomczak, 2017).

Anchoring effect was observed for general knowledge tasks (e.g. Epley and Gilovich, 2001; McElroy and Dowd, 2007; Mussweiler and Strack, 1999), probability estimates (Plous, 1989; Chapman and Johnson, 1999), legal judgements (Englich and Mussweiler, 2001), negotiation (Galinsky and Mussweiler, 2001), price estimates (e.g. Mussweiler et al., 2000), or the evaluation of lotteries and gambling (Chapman, Johnson, 1994).

Anchoring effect was also documented in studies concerning declared preferences, especially willingness to pay (WTP) for specific goods. This kind of research differs 
from the classic anchoring tasks, because valuation tasks do not have a "correct answer". In valuation anchoring tasks, respondents concentrate on their preferences and the utility of the presented items (Yoon et al., 2019). It is worth mentioning that these papers are not particularly common in the literature and typically involve hypothetical choices.

Early examples of experiments on the anchoring effect in valuation include Johnson and Schkade's (1989) study on certainty equivalents of abstract lotteries and studies by Kahneman and Knetsch (1993) and Green et al. (1998) on WTP for public goods.

One of the most important experiments with valuation tasks was conducted by Ariely et al. (2003). Using the incentive compatible Becker-DeGroot-Marschak (BDM) mechanism (Becker et al., 1964), researchers discovered a very strong anchoring effect in the valuation of several consumer goods such as wine or small electronic items, as well as unpleasant experiences (annoying sounds). However, the robustness of these results is limited - subsequent studies presented inconsistent findings when using slightly modified experimental procedures. Tufano (2010), Bergman et al. (2010), Maniadis et al. (2014), and Yoon et al. (2019) reported weaker effects; Simonson and Drolet (2004) identified the moderate impact of the anchor on WTP (but not WTA-willingness to accept) for consumer goods; Fudenberg et al. (2012) failed to find any significant effects of anchors for any of the six items presented; Alevy et al. (2015) found no anchoring effect on WTP values for collectible sports cards and peanuts. The authors of the above-mentioned papers do not provide a comprehensive explanation for this incontinency. Some of them suggest, however, that it might be caused mainly by differences in experimental protocol, such as recruitment method, evaluated goods, or anchor used. They also consider sampling variation and other unobserved differences between studies.

In my study, I examine the robustness of anchoring effect in valuation tasks. Variation in the magnitude of the anchoring effects across studies may be caused by procedural differences, such as the use of financial incentives. Some anchoring studies demonstrated that incentives reduce the anchoring effect (Simmons et al., 2010; Sugden et al., 2013). Other likely sources of inconsistency in anchoring studies include sampling variation and the availability of information about the product. Some researchers have also pointed out that the value and type of anchor may affect the way it operates. For example, Sugden et al. (2013) observed that anchor affected valuation only when it was framed as a plausible price of the good. Epley and Gilovich (2001) demonstrated that different mechanisms underlying the anchoring effect are activated under different contexts, influencing the magnitude of the anchoring effect. When the anchor values are self-generated by participants, adjustment process is 
activated; when anchors are provided externally (for example by experimenter), the mechanism of selective accessibility is activated. Some studies considered also potential human factors which influenced the susceptibility to the anchoring effect. Bergman et al. (2010) showed that anchoring effect increased with higher cognitive ability of participants; Bodenhausen et al. (2000) found that participants in sad mood were more susceptible to the anchoring effect (in comparison with people in happy or neutral mood); Wilson et al. (1996) discovered that the anchoring effect is weakened when participants are knowledgeable.

In this paper, I examine if the anchoring effect is robust to procedural differences. I study the operation of anchoring with respect to the method of eliciting consumer WTP, the type of anchor, and accessibility of information about the presented product. I hypothesized that anchoring effect influences the WTP for private consumer goods. I expected that participants who were shown a high anchor would report a higher WTP for the presented good than those who were shown a low anchor (or no anchor). I also expected that anchoring effect would be stronger in experiments with hypothetical valuation comparing to the experiments with actual purchasing transactions.

\section{DESIGN AND PROCEDURES}

I sought to verify the robustness of the anchoring effect in various conditions and circumstances. Consequently, I studied the impact of the anchors on the valuation of private consumer goods. I conducted four laboratory experiments. In each of them, the participants (all of which were female, aged ca. 21 on average) were asked to state their WTP for a mascara. It is a familiar, commonly used good, but there is a great variety of brands and models, ranging in price from 10 PLN to approx. 200 PLN. I chose Cover Girl Lash Blast Clump Crusher mascara, which is not available in cosmetic shops in Poland (and is rarely accessible online). I could thus expect that the participants would not know the actual market price (57.40 PLN, or 13.30 EUR, in an online shop in November 2016) and so could not use it as a home-grown anchor or reference point. Post-experiment questionnaires confirmed that only a small minority were familiar with the brand or, smaller still, with the model.

All of my experiments were paper-and-pencil and were conducted at the Faculty of Economics at a large and nationally prestigious university in Central and Eastern Europe. 


\section{Experiment 1: Low vs. high anchor in an incentivised auction}

Two different treatments were used in this experiment: Low (with low anchor) and $\mathrm{Hi}$ (with high anchor). Hi or Low anchors were randomly assigned to each individual within a session.

At the beginning of the session, the participants were informed about the basic principles of the experiment (for more details, see the Appendix), before the product was shown to them. The participants were randomly divided into groups of six and took part in a second-price sealed-bid (Vickrey) auction. Vickrey auction is one of the most commonly used demand-revealing techniques in experimental economics (e.g. Irwin et al., 1992, Nunes and Boatwright, 2004, List, 2001). It is incentive compatible - the weakly dominant strategy in this type of auction is to reveal the true WTP for the object (Vickrey, 1961, Kagel, 1995). The participants were informed about the rules of the auction both orally and in writing (see the Appendix). Afterwards, the auction questionnaires (with information about the anchor price) were distributed, the auction was held, and actual transactions were executed. The participants who won the auctions purchased the mascaras and paid for them with their own money.

In order to test the anchoring effect, I compared the Low (20 PLN) vs. High (70 PLN) anchors. Either was presented to the participants as a guess concerning the market price of the mascara provided by a participant in a similar experiment, thus no deception was used. It is worth mentioning that the participants were not explicitly asked whether their WTP was greater or smaller than the given price, which may have weakened the anchoring effect (Brewer and Chapman, 2002; Mochon and Frederick, 2013). However, this kind of comparison between the anchor and the target seems unnatural because the questions become redundant; see the discussion in Mochon and Frederick (2013).

At the end of the experiment, the participants were asked to fill in the postexperimental questionnaire covering consumer habits, their preferences with regard to cosmetics, and sociodemographic characteristics.

It took approximately fifteen minutes for each session to be conducted. Participants were given both written and oral instructions. In total, 47 local students took part in the study.

\section{Results of Experiment 1}

The mean value of WTP for the mascara across the sample as a whole was equal to 13.68 PLN, with a median of 12 PLN and standard deviation of 7.22 PLN. I therefore begin my analysis by comparing the WTP values in each treatment, see Table 1 and Figure 1. 
Table 1

Experiment 1: Descriptive statistics (monetary values in PLN)

\begin{tabular}{ccc}
\hline & Low & Hi \\
\hline Mean & 12.17 & 15.26 \\
\hline Median & 10 & 16 \\
\hline Standard Deviation & 7.68 & 6.51 \\
\hline $\boldsymbol{N}$ & 24 & 23 \\
\hline
\end{tabular}

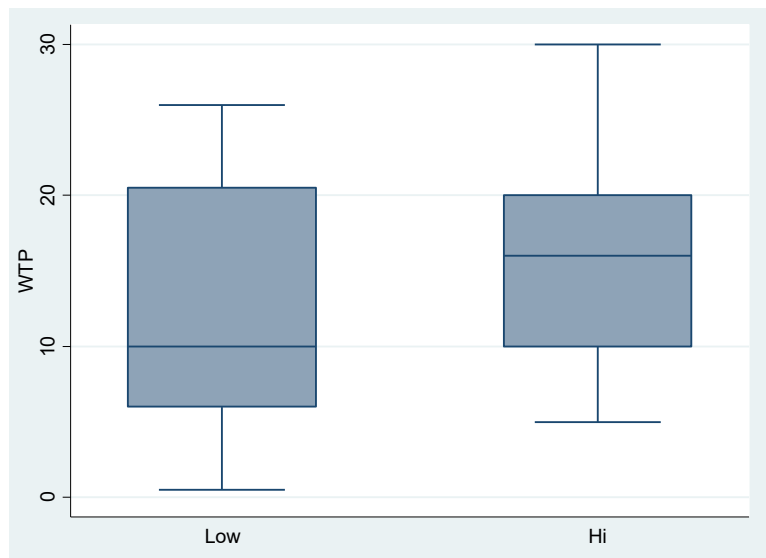

Figure 1. Experiment 1: WTPs by treatment (in PLN)

From the visual inspection alone, the anchor makes little difference. I verified this observation using non-parametric Mann-Whitney U test. Differences between the mean values of WTP in Low and Hi treatments are not statistically significant (). In light of these results, I can confidently state that the anchor does not affect the valuation of mascaras - there was no anchoring effect.

As previously mentioned, the vast majority of studies on anchoring have used hypothetical questions. It is thus possible that the unexpected null result was caused by the use of real incentives. To verify if this is indeed the case, I modified my method in Experiment 2.

\section{Experiment 2: Low vs. high anchor in hypothetical conditions}

The design of Experiment 2 was similar to that of Experiment 1, but instead of a second-price sealed-bid (Vickrey) auction with real transactions, hypothetical valuations were elicited. Having seen the product and a High or Low anchor analogous to those of Experiment 1, the participants were asked: Give the maximum 
price that you would be willing to buy CoverGirl LashBlast Clump Crusher mascara for (in PLN)? Again, at the end of the experiment I asked participants to complete the same questionnaire.

It took roughly fifteen minutes for each session to be conducted. I used both written and oral instructions. In total, 51 local students took part.

\section{Results of Experiment 2}

The mean value of WTP for the mascara across the sample as a whole was equal to 22.45 PLN, with a median of 22 PLN and standard deviation of 9.29 PLN. The comparison of WTP values by treatment is provided in Table 2 and Figure 2.

Table 2

Experiment 2: Descriptive statistics (monetary values in PLN)

\begin{tabular}{ccc}
\hline & Low & Hi \\
\hline Mean & 23.00 & 21.92 \\
\hline Median & 23 & 20 \\
\hline Standard Deviation & 8.83 & 9.86 \\
\hline $\boldsymbol{N}$ & 25 & 26 \\
\hline
\end{tabular}

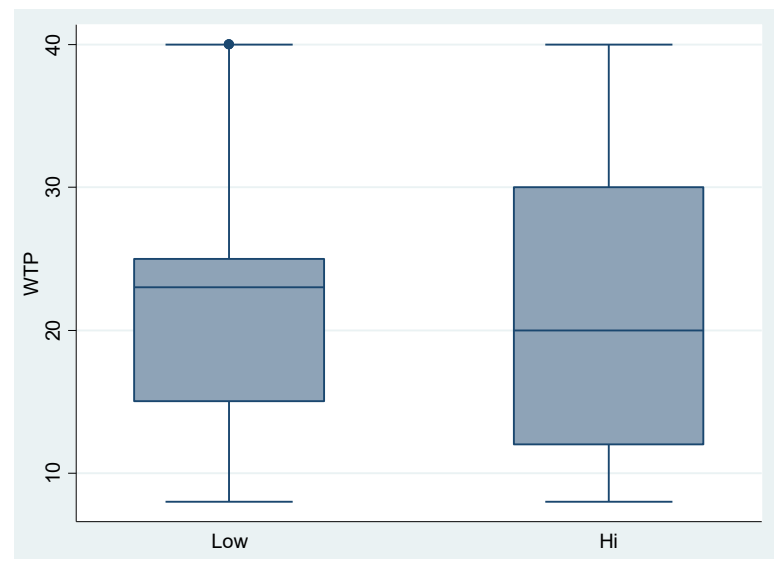

Figure 2. Experiment 2: WTPs by treatment (in PLN)

At first glance, the anchor made little difference. I verified this observation using non-parametric Mann-Whitney U test. According to this test, the medians of WTP in treatments with low and high anchors are equal $(z=.379, p=.705)$. To summarise my findings, no anchoring effect could be detected. 
However, I suspect that the results of Experiments 1 and 2 may be due to the type of anchor used. It is possible that the participants did not take the anchor particularly seriously, because it was merely another participant's valuation. As a result, it did not affect their final valuation. The observed null results may also have been caused by the relatively small size of the sample at hand. To check my conjectures, I conducted another experiment.

\section{Experiment 3. High anchor vs. no anchor in an incentivised auction}

The design of Experiment 3 was very similar to the design used in Experiment 1, with two main differences. First, I used a stronger anchor: the real market price of a similar product - Cover Girl Lash Blast Volume mascara. Its price is 68.42 PLN, very close to the high anchor of Experiment 1, and generally exceeds most participants' valuations. I used this high anchor only, comparing it to no anchor at all, because there are no comparable mascaras on the market at a much lower price, so it was impossible to use a low market-price anchor without deception.

Second, the participants received more detailed information concerning the presented item. Specifically, at the beginning of the experiment, two TV advertisements were displayed and the mascaras were passed around for the participants to see up close (but not try out). This modification may have made the valuation process more similar to actual purchasing processes.

Two different treatments were used in this experiment: Hi (with a high anchor) and No (with no anchor). The participants were randomly divided into groups of six and took part in a Vickrey auction with real purchasing transactions. It took about twenty minutes for each session to be conducted. Participants were given written instructions only. This time a larger sample of 138 local students took part.

\section{Results of Experiment 3}

The mean value of WTP for the mascara in the whole sample equalled 29.04 PLN with a median of 25 PLN and standard deviation of 18.46 PLN. Table 3 and Figure 3 illustrate WTP by treatment.

Table 3

Experiment 3: Descriptive statistics (monetary values in PLN)

\begin{tabular}{ccc}
\hline & No & Hi \\
\hline Mean & 27.28 & 30.66 \\
\hline Median & 22.25 & 25 \\
\hline Standard Deviation & 20.56 & 16.28 \\
\hline $\boldsymbol{N}$ & 66 & 72 \\
\hline
\end{tabular}




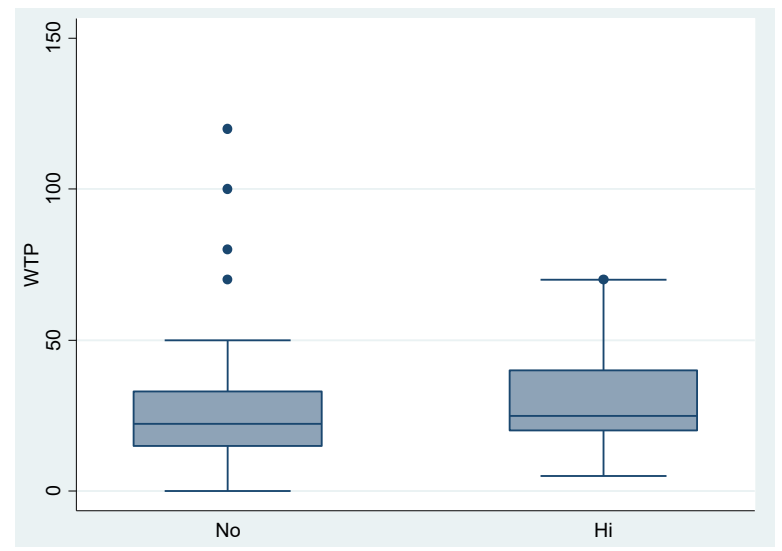

Figure 3. Experiment 3: WTPs by treatment (in PLN)

Again, Mann-Whitney's non-parametric test was used to compare treatments. The differences between mean WTP in groups with a high anchor and without an anchor are borderline insignificant (). I suspect that, again, the anchor does not affect the valuation of mascaras.

To check if this result is due to the auction technique used in the experiment, I used the declarative method of eliciting consumer WTP in Experiment 4.

\section{Experiment 4: High anchor vs. no anchor in hypothetical conditions}

This experiment was conducted simultaneously with Experiment 3 (I used written instructions only to mitigate the possibility of contamination). Again, two different treatments were used in this experiment: Hi (with high anchor) and No (with no anchor). Participants were randomly assigned to the Hi or No conditions. In Experiment 4, the scheme was similar to that of Experiment 3, but instead of a Vickrey auction, hypothetical WTPs were elicited (using the same question as described in Experiment 2).

It took approximately twenty minutes for each session to be conducted. In total, 150 local students took part.

\section{Results of Experiment 4}

The mean value of WTP for the mascara across the sample as a whole equalled 36.37 PLN with a median of 35 PLN and standard deviation of 12.78 PLN. Table 4 and Figure 4 compare WTP values by treatment. 
Table 4

Experiment 4: Descriptive statistics (monetary values in PLN)

\begin{tabular}{ccc}
\hline & No & Hi \\
\hline Mean & 33.99 & 38.81 \\
\hline Median & 34.5 & 35.45 \\
\hline Standard Deviation & 11.28 & 13.82 \\
\hline $\boldsymbol{N}$ & 76 & 74 \\
\hline
\end{tabular}

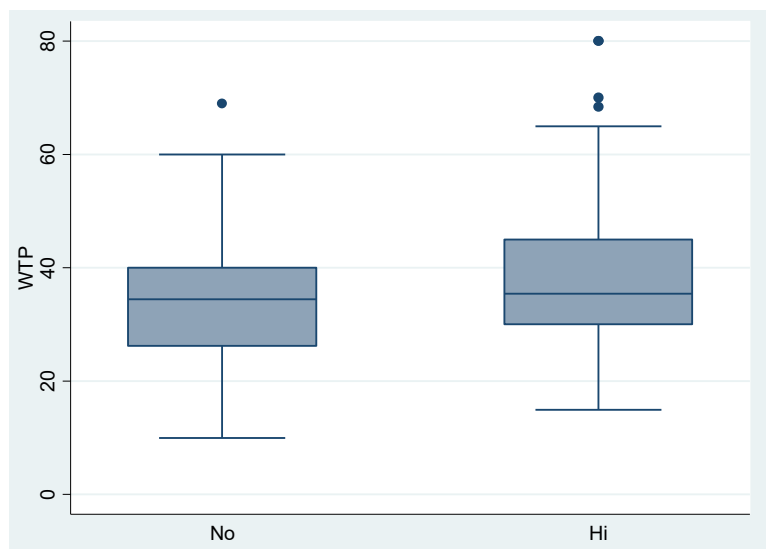

Figure 4. Experiment 4: WTPs by treatment (in PLN)

From the visual inspection alone, the anchor affects the valuation of mascaras. To verify this observation, I performed Mann-Whitney U test. According to this test, the differences between WTP values in the Hi and No treatments are statistically significant $(z=-2.053, p=.040)$. In light of this result, I am able to state that the anchoring effect occurs. Participants who were shown a High anchor reported a higher WTP for the good than those shown a low anchor.

\section{Conclusions}

I examined the anchoring effect in four laboratory experiments differing in their method of eliciting consumer WTP, type of anchor, and the availability of information about the presented product. I observed that the anchor affected the participants' WTP values in only one of the four experiments conducted. I found a significant anchoring effect in Experiment 4, and a borderline insignificant effect in Experiment 3. In light of these findings, I can state that the strength of the effect 
may depend on the type of anchor used and that not all anchors are effective. Only the market anchor (the real price of a similar product) affected WTP in my study. One reason for that may have been that participants were not explicitly asked to indicate whether they would be willing to purchase the product at the anchor price. Participants may have been disinclined to seriously consider the weaker anchor provided to them in Experiments 1 and 2 (another participant's valuation), so this anchor did not affect their WTP values.

I can also suppose that the magnitude of the anchoring effect is lower in incentivised valuation tasks compared to the hypothetical anchoring questions. Anchors made a substantial difference only in the declarative valuation (Experiment 4). I hypothesise that in an auction with real transactions, participants were sufficiently incentivised to modify the most directly available value and, as a result, the anchoring effect did not occur. This finding contributes to the discussion of the mechanism underlying the anchoring effect, implying that the anchoring effect may be caused by insufficient conscious efforts to drift away from the anchor (Gilbert et al., 1988; Kruger; 1999). Therefore, my result seems to be in opposition to the strand of research suggesting that information consistent with the anchor provided by the experimenter is more accessible (Strack and Mussweiler, 1997), thus the bias is not affected by deliberation (e.g. manipulated by incentives, warnings, or time pressure). Instead, in my study I demonstrated that the anchoring mechanism is relatively susceptible to the provision of financial incentives.

My findings suggest the limits of robustness of the anchoring effect. One possible explanation is provided by Simonson (2008) and Simonson and Rosen (2014). These authors suggest that technology influences the "value-maximization" - fundamental process of consumer behaviour (choosing the product or service with the highest subjective perceived value for the price paid). Due to the common access to the Internet, price comparison apps and other emerging technologies, modern consumers have access to potentially unlimited and perfect information, which makes the valuemaximization easier. As a result, consumers are increasingly rational and may be less susceptible to traditional marketing activities, as well as decision phenomena, heuristics and cognitive biases, such as anchoring effect.

Simonson (2008) discusses the consumer susceptibility to various decision phenomena (such as anchoring effect), referring to the division of consumer preferences into inherent and constructed ones. Constructed preferences are created when decision are made and they are determined by the choice context, preference elicitation method, tasks characteristics and the description of options. Inherent preferences refers to relatively stable preference components that are predetermined and not influenced by context. The constructed component of preferences is most 
important for yet non-experienced preference objects (when consumer has no earlier experience with the product or service) or for objects with relatively little experience feedback. In this case, consumer preferences are very susceptible to reference points, marketing activities and other construction forces. Conversely, inherent preferences are most influential for experienced objects (for example familiar, commonly used products). In my study, the participants had a lot of experience with the valuated product (as a type, not specific model or brand), so their preferences seem to be only moderately susceptible for forces of preference construction, such an anchoring.

I am aware of limitations of the experimental procedure used in the experiments reported here, which jointly mean that some extrapolations of the observed results may only be done with caution. First, student samples were used in all the experiments. The meta-analysis conducted by Peterson (2001) showed that this type of sample is more homogenous than other ones, but generalizing from students to general public may be problematic in view of differences of the effect sizes observed for student and nonstudent subjects. Due to the nature of the product used, all participants were female; results for men could be slightly different (see Croson and Gneezy, 2009). Moreover, sample sizes in experiments 1 and 2 were small, which could partly explain the null results obtained. Another reason behind the null result could be that the participants were not directly asked to consider if their WTP was lower or higher than the anchor value (or to consider whether they would be willing to purchase the product at the anchor price). This somewhat less often practiced way in which the anchors were presented could potentially weaken the anchoring effect obtained (Brewer and Chapman, 2002; Mochon and Frederick, 2013).

In conclusion, to find the specific factors that influence the robustness of anchoring effect, further investigation is needed. Conducting this type of study with a more diverse sample (rather than a sample of students) and different product categories, which would allow extrapolating the results to others social groups and make the findings more universal.

To sum up, presented results confirm the inconsistency of the anchoring effect in valuation tasks (Bergman et al., 2010; Fudenberg et al., 2012; Maniadis et al., 2014). Although anchoring effect can influence the WTP for private consumer goods, it is not robust to procedural differences in studies on the subject. 


\section{REFERENCES}

Alevy, J.E., Landry, C.E., List, J.A. (2015). Field Experiments on Anchoring of Economic Valuations. Economic Inquiry, 53(3), 1522-1538. 10.1111/ecin.12201

Ariely, D., Loewenstein, G., Prelec, D. (2003). 'Coherent Arbitrariness': Stable Demand Curves without Stable Preferences. Quarterly Joumal of Economics, 118(1), 73-106. 10.1162/00335530360535153

Becker, G.M., DeGroot, M.H., Marschak, J. (1964). Measuring utility by a single-response sequential method. Behavioral science, 9(3), 226-232.

Bergman, O., Ellingsen, T., Johannesson, M., Svensson, C. (2010). Anchoring and Cognitive Ability. Economics Letters, 107 (1), 66-68. 10.2307/1061360

Bodenhausen, G.V., Gabriel, S., \& Lineberger, M. (2000). Sadness and susceptibility to judgmental bias: The case of anchoring. Psychological Science, 11(4), 320-323.

Brewer, N.T. Chapman, G.B. (2002). The fragile basic anchoring effect. Journal of Behavioral Decision Making, 15(1), 65-77. 10.1002/bdm.403

Chapman, G.B., Johnson, E.J. (1994). The limits of anchoring. Journal of Behavioral Decision Making, 7, 223-42. 10.1002/bdm.3960070402

Chapman, G.B., Johnson, E.J. (1999). Anchoring, activation, and the construction of values. Organizational Behavior and Human Decision Processes, 79(2), 115-153. 10.1006/obhd.1999.2841

Croson, R. and Gneezy, U. (2009). Gender differences in preferences. Journal of Economic Literature, 47(2), 448-474.

Englich, B., Mussweiler, T. (2001). Sentencing under Uncertainty: Anchoring Effects in the Courtroom. Journal of Applied Social Psychology, 31, 1535-1551. 10.1111/j.1559-1816.2001.tb02687.x

Epley, N., Gilovich, T. (2001). Putting adjustment back in the anchoring and adjustment heuristic: Differential processing of self-generated and experimenter-provided anchors. Psychological Science, 12(5), 391-396. 10.1111/1467-9280.00372

Frederick, S.W., Mochon, D. (2012). A scale distortion theory of anchoring. Journal of Experimental Psychology: General, 141(1), 124.

Fudenberg, D., Levine, D.K., Maniadis, Z. (2012). On the Robustness of Anchoring Effects in WTP and WTA Experiments. American Economic Journal: Microeconomics, 4(2), 131-145. 10.1257/ mic.4.2.131

Galinsky, A.D., Mussweiler, T. (2001). First offers as anchors: the role of perspective-taking and negotiator focus. Journal of Personality and Social Psychology, 81(4), 657-669. 10.1037/00223514.81.4.657

Gilbert, D.T., Pelham, B.W., Krull, D.S. (1988). On cognitive busyness, when busy perceivers meet persons perceiving. Journal of Personality and Social Psychology, 54, 733-740. 10.1037/00223514.54.5.733

Green, D., Jacowitz, K. E., Kahneman, D., McFadden, D. (1998). Referendum Contingent Valuation, Anchoring, and Willingness to Pay for Public Goods. Resources and Energy Economics, 20, 85116. 10.1016/S0928-7655(97)00031-6

Irwin, J.R., McClelland, G.H., Schulze, W.D. (1992). Hypothetical and real consequences in experimental auctions for insurance against low-probability risks. Journal of Behavioral Decision Making, 5(2), 107-116. 10.1002/bdm.3960050203 
Johnson, E.J., Schkade, D.A., (1989). Bias in Utility Assessments: Further Evidence and Explanations. Management Science, 35(4), 406-424. 10.1287/mnsc.35.4.406

Kagel, J. (1995). Auctions: A Survey of Experimental Research. In J. Kagel, and A.E. Roth (Eds.), Handbook of Experimental Economics, 501-585.

Kahneman, D., Knetsch, J. (1993). Anchoring or Shallow Inferences: The Effect of Format. Unpublished manuscript. University of California, Berkeley.

Kruger, J. (1999). Lake Wobegon be gone! The "below-average effect" and the egocentric nature of comparative ability judgments. Journal of Personality and Social Psychology, 77, 221-232. 10.1037//0022-3514.77.2.221

List, J.A. (2001). Do Explicit Warnings Eliminate the Hypothetical Bias in Elicitation Procedures? Evidence from Field Auctions for Sportscards. American Economic Review, 91(5), 1498-1507. 10.1257/aer.91.5.1498

Maniadis, Z., Tufano, F., List, J.A. (2014). One Swallow Doesn't Make a Summer: New Evidence on Anchoring Effects. American Economic Review, 104(1), 277-290. 10.1257/aer.104.1.277

McElroy, T., Dowd, K. (2007). Susceptibility to anchoring effects: How openness-to-experience influences responses to anchoring cues. Judgment and Decision making, 2(1), 48.

Mochon, D., Frederick, S. (2013). Anchoring in sequential judgments. Organizational Behavior and Human Decision Processes, 122(1), 69-79. 10.1016/j.obhdp.2013.04.002

Mussweiler, T., Strack, F. (1999). Hypothesis-consistent testing and semantic priming in the anchoring paradigm: A selective accessibility model. Journal of Experimental Social Psychology, 35, 136-164. 10.1006/jesp.1998.1364

Mussweiler, T., Strack, F., Pfeiffer, T. (2000). Overcoming the inevitable anchoring effect: Considering the opposite compensates for selective accessibility. Personality and Social Psychology Bulletin, 26, 1142-1150. 10.1177/01461672002611010

Nunes, J.C., Boatwright, P. (2004). Incidental prices and their effect on willingness to pay. Journal of Marketing Research, 41(4), 457-466. 10.1509/jmkr.41.4.457.47014

Peterson, R.A. (2001). On the use of college students in social science research: Insights from a second-order meta-analysis. Journal of consumer research, 28(3), 450-461.

Plous, S. (1989). Thinking the unthinkable: The effect of anchoring on likelihood estimates of nuclear war. Journal of Applied Social Psychology, 19, 67-91. 10.1111/j.1559-1816.1989.tb01221.x

Simmons, J.P., LeBoeuf, R.A., Nelson, L.D. (2010). The effect of accuracy motivation on anchoring and adjustment: Do people adjust from provided anchors? Journal of Personality and Social Psychology, 99(6), 917-932. 10.1037/a0021540

Simonson, I. (2008). Will I like a "medium" pillow? Another look at constructed and inherent preferences. Journal of Consumer Psychology, 18(3), 155-169.

Simonson, I., Drolet, A. (2004). Anchoring Effects on Consumers' Willingness-to-Pay and Willingnessto-Accept. Journal of Consumer Research, 31(3), 681-690. 10.1086/425103

Simonson, I., Rosen, E. (2014). Absolute value: What really influences customers in the age of (nearly) perfect information. New York: HarperBusiness.

Sugden, R., Zheng, J., Zizzo, D.J. (2013). Not all anchors are created equal. Journal of Economic Psychology, 39(C), 21-31. 10.1016/j.joep.2013.06.008 
Strack, F., Mussweiler, T. (1997). Explaining the enigmatic anchoring effect: Mechanisms of selective accessibility. Journal of personality and social psychology, 73(3), 437.

Tomczak, P. (2017). Dlaczego kotwica kotwiczy? Przegląd mechanizmów i zasad działania heurystyki zakotwiczenia. Decyzje, 28, 93-110.

Tufano, F. (2010). Are 'True' Preferences Revealed in Repeated Markets? An Experimental Demonstration of Context-Dependent Valuations. Experimental Economics, 13(1), 1-13. 10.1007/ s10683-009-9226-8

Tversky, A., Kahneman, D. (1974). Judgment under uncertainty: Heuristics and biases. Science, 185(4157), 1124-31. 10.1126/science.185.4157.1124

Vickrey, W. (1961). Counterspeculation, Auctions, and Competitive Sealed Bids. Journal of Finance, 16, 8-37. 10.1111/j.1540-6261.1961.tb02789.x

Wegener, D.T., Petty, R.E., Detweiler-Bedell, B.T., Jarvis, W.B.G. (2001). Implications of attitude change theories for numerical anchoring: Anchor plausibility and the limits of anchor effectiveness. Journal of Experimental Social Psychology, 37(1), 62-69.

Wilson, T.D., Houston, C.E., Etling, K.M., \& Brekke, N. (1996). A new look at anchoring effects: basic anchoring and its antecedents. Journal of Experimental Psychology: General, 125(4), 387.

Yoon, S., Fong, N. M., Dimoka, A. (2019). The robustness of anchoring effects on preferential judgments. Judgment and Decision Making, 14(4), 470.

\section{APPENDIX}

\section{Transcription of instructions}

\subsection{Experiment 1}

\section{Part 1: intro [presented orally]}

Welcome!

Thank you for taking part in our experiment! A randomly drawn participant will receive a gift today.

Please turn off your mobile phones, remain silent, and do not communicate with one another.

If you have any questions during the experiment, raise your hand and wait for the experimenter to come to you (do not ask your question aloud).

People who do not comply with these rules will be excluded from the experiment and lose their chance of winning the prize.

We would like to inform you that the study is anonymous and all data collected will be used solely for scientific purposes. Along with the next instruction, you will receive an individual respondent code that you will need until the end of the experiment. Put it in a prominent spot on the bench/desktop in front of you. 


\section{Part 2: rules}

In a moment you will have an opportunity to buy a cosmetic product. You will be randomly matched into groups of six. A second-price (Vickrey) auction will be conducted within each group. Each participant will receive a valuation questionnaire and will place her bid. The amount you give will not be disclosed to anyone. The bids will then be collected and ranked from highest to lowest. The highest bidder will win the auction. The experimenter will sell her presented product, not at the price she declared but at the price of the second highest bid.

The best strategy in this kind of auction is to give your actual valuation, which is the maximum price you are willing to buy the presented product for.

Example:

Six people participating in the auction made the following bids:

Person 1: A PLN

Person 2: B PLN

Person 3: C PLN

Person 4: D PLN

Person 5: E PLN

Person 6: F PLN

The bids were then ranked from highest to lowest.

If, for example, $\mathrm{A}>\mathrm{C}>\mathrm{E}>\mathrm{F}>\mathrm{B}>\mathrm{D}$, then the winner of the auction will be Person 1, because she gave the highest bid (A PLN). She will buy the presented product, paying for it the second highest price, which is C PLN.

The auction results will be announced at the end of the experiment. The winning person will be required to make a purchase in accordance with the aforementioned rules. If you win the auction and you do not have enough money with you, you will be able to pay within a week of the experiment. Thus even if you do not have cash on you, you can still participate in the auction.

If you have any questions, raise your hand and wait for the experimenter to approach you.

\section{Part 3: valuation [Low, Hi]}

One participant in a similar study said she thought the presented product would normally sell at [20/70] PLN.

Remembering that you are participating in an auction, give the maximum price you are willing to buy CoverGirl LashBlast Clump Crusher Mascara for. (Please enter a specific amount in PLN.) 


\subsection{Experiment 2}

\section{Part 1: intro [presented orally]}

[the same as in Experiment 1]

\section{Part 2: rules}

In a moment, you will receive a questionnaire in which you will be asked to value a cosmetic product. In the questionnaire, you will have to specify the maximum price you would be willing to pay for this product. Your reply will be purely declarative and no real transactions will be made on this basis. The amount you give will not be disclosed to anyone.

If you have any questions, raise your hand and wait for the experimenter to approach you.

\section{Part 3: valuation [Low, Hi]}

One participant in a similar study said she thought the presented product would normally sell at [20/70] PLN.

Give the maximum price that you would be willing to buy CoverGirl LashBlast Clump Crusher mascara for? (Please enter a specific amount in PLN.)

\subsection{Experiment 3}

\section{Part 1: intro}

Welcome!

Thank you for taking part in our experiment! A randomly drawn participant will receive a 50 PLN Sephora voucher today.

Please turn off your mobile phones, remain silent, and do not communicate with one another.

If you have any questions during the experiment, raise your hand and wait for the experimenter to come to you (do not ask your question aloud).

People who do not comply with these rules will be excluded from the experiment and lose their chance of winning the prize.

We would like to inform you that the study is anonymous and all data collected will be used solely for scientific purposes. Along with the next instructions, you will receive an individual respondent code that you will need until the end of the experiment. Put it in a prominent spot on the bench/desktop in front of you. 


\section{Part 2: rules [No, $\mathrm{Hi}]$}

You've just seen advertisements for CoverGirl LashBlast Clump Crusher mascara. You have also had an opportunity to see this product up close. [Hi: A similar product to CoverGirl brand, CoverGirl Lash Blast Volume mascara, would sell at 68.42 PLN (Nov. 2015, online pharmacy premiumusa.pl).]

In a moment, you will have an opportunity to buy the presented mascara. You will be randomly matched into groups of six. A second-price (Vickrey) auction will be conducted within each group. Each participant will receive a valuation questionnaire and will place her bid. The amount you give will not be disclosed to anyone. Then the bids will be collected and ranked from highest to lowest. The highest bidder will win the auction. The experimenter will sell her presented product, not at the price she declared but at the price of the second highest bid.

The best strategy in this kind of auction is to give your actual valuation, which is the maximum price you are willing to buy the presented product for.

Example:

Six people participating in the auction made the following bids:

Person 1: A PLN

Person 2: B PLN

Person 3: C PLN

Person 4: D PLN

Person 5: E PLN

Person 6: F PLN

The bids were then ranked from highest to lowest.

If, for example, $\mathrm{A}>\mathrm{C}>\mathrm{E}>\mathrm{F}>\mathrm{B}>\mathrm{D}$, then the winner of the auction will be Person 1, because she gave the highest bid (A PLN). She will buy the presented product, paying for it the second highest price, that is C PLN.

The auction results will be announced at the end of the experiment. The winning person will be required to make a purchase in accordance with the above rules. If you win the auction and you do not have enough money with you, you will be able to pay within a week of the experiment. Thus even if you do not have cash on you, you can still participate in the auction.

If you have any questions, raise your hand and wait for the experimenter to approach you. 


\section{Part 3: valuation}

Give the maximum price you are willing to buy CoverGirl LashBlast Clump Crusher mascara for. (Please enter a specific amount in PLN.)

\subsection{Experiment 4}

\section{Part 1: intro}

[the same as in Experiment 3]

\section{Part 2: rules [No, $\mathrm{Hi}]$}

You've just seen advertisements for CoverGirl LashBlast Clump Crusher mascara. You have also had an opportunity to see this product up close. [Hi: A similar product of CoverGirl brand, CoverGirl Lash Blast Volume mascara, would sell at 68.42 PLN (Nov. 2015, online pharmacy premiumusa.pl).]

In a moment, you will receive a questionnaire in which you will be asked to value the presented product. In the questionnaire, you will have to specify the maximum price you would be willing to pay for CoverGirl LashBlast Clump Crusher mascara. Your reply will be purely declarative and no real transactions will be made on this basis. The amount you give will not be disclosed to anyone.

If you have any questions, raise your hand and wait for the experimenter to approach you.

\section{Part 3: valuation}

Give the maximum price that you would be willing to buy CoverGirl LashBlast Clump Crusher mascara for? (Please enter a specific amount in PLN.) 